\title{
CIPHI Members Provide Invaluable Service and Education to Those Impacted by the Alberta Flood
}

\author{
Andrew Papadopoulos (with files from Meaghen Allen, Greg Harris, Angella Kim, and Jason MacDonald)
}

Ref: EHR Vol. 56(2) 28-29 DOI: 10.5864/d2013-018

"Because public health inspectors are nationally certified, Alberta Health Services was able to accept help from British Columbia and Saskatchewan and was confident in the skills and abilities of public health inspectors from those jurisdictions as those helping from different provinces have the same level of training."

I want to personally acknowledge the omission, albeit unintentional, of the contributions made by members from Manitoba and other jurisdictions within this very informative article. The flooding in Southern Alberta in the spring of 2013 was an unprecedented event that impacted many of our members both professionally and personally. It became apparent that staff throughout the province would need to be reassigned and additional staff would likely be required. Support from adjacent provinces and retirees was integral to the excellent service we were able to provide to the public.

I stand behind the comment that "This is (was) a real opportunity to showcase our profession". Immediately after learning of the devastation caused by floodwaters, our communities became well aware of the role $\mathrm{CPHI}(\mathrm{C})$ holders have in protecting their health. Having nationally recognized certification enabled inspectors from other provinces to assist Alberta. We are fortunate to be part of an organization that has a continuing professional competencies program and enables our skills to be transferable nationally. As we work toward requiring mandatory membership, we need to remember that maintaining our professional development hours and maintaining membership in the Institute strengthens our credentials. As we enter our PDHs, we should take a minute to embrace the value of belonging to an Institute that ensures we are recognized as highly trained professionals with a unique set of skills.

Jason A. MacDonald, B.Sc, CPHI(C)

President, CIPHI Alberta Branch 